\title{
Conceptual Model of Green Construction toward Construction waste Reduction (A System Dynamic-Based Concept)
}

\author{
Muhammad Zulfikar \\ Sepuluh Nopember Institute of Technology, Indonesia
}

\begin{abstract}
The challenges facing global society this century are environmental problems, one of which is caused by waste. Based on this, Indonesia should make construction waste a serious concern and on the other hand Indonesia must continue its development activities, especially construction in ways that pay attention to the environment in order to provide space for decent living for future generations. A blueprint for the construction sector was drawn up as a grand design and grand strategy called Indonesian Construction 2030. One of the proposed agendas was to promote sustainable construction through a green construction method aimed at restoring and maintaining environmental balance. However, the implementation of green construction which is still limited and has not yet reached the system level is an issue that needs attention and the most crucial part of green construction is that the effect on the environment, especially construction waste, is unclear. The purpose of this study is to develop a conceptual model of the relationship between green construction and reduction of construction waste. The methodology used in this study is intensive literature review. The results of this study will be used to develop a conceptual model of the relationship between the application of green construction to the reduction of construction waste. The results of this study show a dynamic system-based conceptual model of the relationship between the factors of the application of green construction to the reduction of construction waste. This research can also provide insights related to the factors of green construction that can significantly reduce construction waste. Can be an important input for all parties to encourage and improve the application of the concept of sustainable development, especially the green construction method.
\end{abstract}

Keywords: green construction, reduction, construction waste, system dynamic. 